Energy

Volume 171 Issue EN1

Transition of Växjö and Sønderborg towards becoming fossil-fuel-free communities

Dyer and Ögmundardóttir
Proceedings of the Institution of Civil Engineers Energy 171 February 2018 Issue EN1 Pages 3-11 https://doi.org/10.1680/jener.17.00004 Paper 1700004

Received 29/01/2017 Accepted 05/10/2017

Published online 01/12/2017

Keywords: energy/town \& city planning

\title{
Transition of Växjö and Sønderborg towards becoming fossill-fuel-free communities
}

1 Mark Dyer BEng, BSC, MA, DPhil, CEng, FICE, FTCD

Professor, Dean of Engineering, University of Waikato, Hamilton, New Zealand (corresponding author: mdyer@tcd.ie)

\author{
2 Helga Ögmundardóttir MA, PhD \\ Lecturer, University of Iceland, Reykjavik, Iceland
}
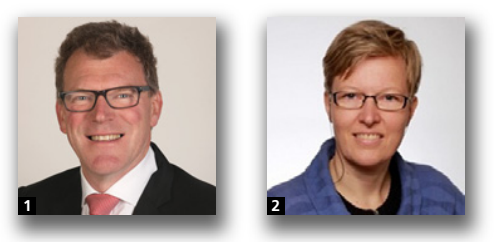

The findings are reported of ethnographic field studies carried out in two Scandinavian cities, namely Sønderborg and Växjö. The field studies investigated actors, networks and motivations that enable the deployment of renewable and energy-efficiency technologies for transition towards a fossil-fuel-free future. The research shows a pattern of different ideas and methods that contributed towards a common vision for significant reduction in energy use and emission. In the case of Växjö, the common narrative was one of protecting and valuing the environment through making good use of local resources, particularly from forestry. However, the theme for Sønderborg was one of job creation and business opportunities brought about by the creation of 'Project Zero' in a formal alliance between private and public sector organisations. Even so, both cities were characterised by dynamic communication and networking backed by political consensus.

\section{Introduction}

Although three-quarters of the global energy demand is estimated to stem from urban populations, and the proportion in western Europe is more than $80 \%$ (Grubler and Buettner, 2012; IEA, 2008), cities have been able to keep a relatively low profile in terms of their specific environmental footprints, and thus evade collective political responsibility. Nevertheless, under the mandate of UN Agenda 21 the local government version, known as 'Local Agenda 21', was implemented in over 1000 cities, towns and counties in 88 countries in terms of sustainable development (Jörby, 2002; Smardon, 2008). The best examples can be found in Europe, where all local governments in Sweden were obliged to implement Local Agenda 21. Yet operating under the umbrella of the national government, cities have become highly globalised and function as relatively free agents to leverage their competitive edge in the external market place while housing a majority of the world's population and thus contributing to global environmental problems.

Strategies for reducing the burning of fossil fuel have largely been led by top-down policy-driven initiatives at government or supra-government level such as the European Commission's Energy Roadmap for 2050 (EC, 2011) and the International Energy Agency's Pathways to a Nordic Carbon Neutral Energy Future (IEA, 2013). Set within a largely neoliberal political landscape, the focus has mainly been on a techno-economic model involving the rapid deployment of renewable energy technologies ranging from wind to biomass, hydro and solar power (Edenhofer et al., 2010a, 2010b; van Sluisveld et al., 2015; von Stechow et al., 2016; Webb et al., 2016). Yet successful deployment of urban energy initiatives is not a matter of technoeconomic optimisation but a process in which the 'social' and the 'technical' are inextricably intertwined, and technologies co-evolve with programmes of governing (Webb et al., 2016). This was highlighted by the recent analysis undertaken by van der Schoor and Scholtens (2015) into the activities of 13 local community energy initiatives in the north of the Netherlands. Using actor network theory, the researchers showed that technology was only one of the actors in the network behind local sustainable energy initiatives. Instead, the study demonstrated that other material and semiotic factors comprising local shared vision, active local networks and connections with external networks were key contributors to local sustainable energy initiatives.

A similar preoccupation with technological solutions can be found in the academic press and scientific publications. Published scientific research mostly focuses on technical solutions and economic models (Dovì and Battaglini, 2015; Edenhofer et al., 2010b; Rizzi et al., 2014; van Sluisveld et al., 2015) when deploying new or improved renewable energy technologies for reductions in greenhouse gas (GHG) emissions 
Transition of Växjö and Sønderborg

towards becoming fossil-fuel-free

communities

Dyer and Ögmundardóttir and consumption of fossil fuels to limit global warming to less than $2^{\circ} \mathrm{C}$. There is still little in the way of published research into public participation and public acceptance when deploying renewable energy, such as new wind energy farms in Japan (Motosu and Maruyama, 2016), constructing new overhead electrical transmission lines (Dovì and Battaglini, 2015; Komendantova et al., 2015) or grass-roots initiatives for community energy sectors (Webb et al., 2016). Blanchet (2015) similarly examined the growing role of grass-roots initiatives in the governance of urban energy systems in Berlin. The study analysed the conflicts over the re-municipalisation of Berlin's electricity grid and investigated the creation and strategic development of two grass-roots initiatives as well as their interaction with the local government and the established grid operator.

As a contribution towards analysing the influence of societal factors on sustainable energy initiatives, this paper provides lessons learnt from an ethnographic field study into the successful deployment of renewable energies at two cities in Scandinavia, namely Växjö in Sweden and Sønderborg in Denmark. Both are medium-sized cities with populations of 79000 and 76000 inhabitants, respectively. Much has already been written about the technological achievements that have taken place at Växjö in terms of building design (Gustavsson and Sathre, 2011; Mahapatra, 2015), district heating (Nguyen Le Truong et al., 2014) and biomass energy generation. Far less has been written about the technical achievements at Sønderborg in Denmark as outlined in the local government report by Kristensen and Dyhr-Mikkelsen (2009). The field studies reported in this paper focus instead on the motivation and behaviour of ordinary members and leaders within each community that have led to the successful deployment of renewable energy systems and energy-efficiency measures. In doing so, the field study aimed to learn from these exemplar projects and draw wider conclusions about the potential to contribute to a low-carbon dioxide energy transition, and how best to seed wider change at the community level.

\section{Field survey methods}

The study is based on qualitative fieldwork carried out in Sønderborg and Växjö during 2013 as well as a literature review of relevant documents and media analysis of local and regional media that put the fieldwork into a socio-economic and cultural context (Neuman, 2014). In line with traditional forms of ethnographic studies, the fieldwork involved the researcher becoming familiar with the stories and narratives for each urban community, that are told in casual conversations as well as in formal interviews, and official texts. As such the fieldwork comprised 19 semi-structured in-depth interviews taken with people involved in the transition, comprising politicians, officials and municipality employees, various nongovernmental organisation (NGO) representatives and individuals from the public, following and/or participating in various associated initiatives. A list of the main topics of conversations held with the different community groups is given in Table 1 . In addition, participant observation was employed by attending meetings and workshops in both municipalities, focusing on carbon dioxide emission reduction, energy savings, and community and environmental issues in general. A careful record was taken of the general public's ideas through casual conversations in the community, in cafés, stores and other such locations and occasions.

Participant observation also involved being in the community for one continuous calendar month, where it was possible to get to know local inhabitants and to listen to their thoughts and stories. These observations allowed the researchers to comprehend the physical landscapes, and become familiar with the social and cultural ups and downs of the community in general. Living and moving around in these cities, by bike, public transport or simply on foot, was a valuable contribution to the understanding and analysis of their change towards a more sustainable and energy-saving future. As such, the way a community treats its green areas, buildings, flora and fauna, water bodies, natural reserves and not least its inhabitants, says more about the actual state of sustainable development than any official document or policy paper.

The principal research questions framing the fieldwork in Växjö and Sønderborg were as follows: (Q1) to what extent do preconditions for implementing energy transitions differed between the two given their diverse approaches to the energy sector; (Q2) to what extent do efforts in transitions enactment depend on different local and regional institutional settings, actors and their strategies. Question Q2 was particularly relevant. These were in turn phrased in more detail in the interview questions used in the semi-structured interviews, although with some variation in focus since the interviewees had quite different positions in the social, economic and cultural fabric. The aim of the project was to map the communities' experience of the ongoing transition to a low-carbon dioxide future and a world of climate change, and therefore the net was cast wide and any upcoming issue considered as important for further scrutiny. The issues highlighted in this paper were chosen because they turned out to be relevant for the unfolding of the transition histories of the communities, and they often reappeared in the media, casual conversations, meetings, official documents and, last but not least, in other scholarly texts from the research field. Other issues, known from similar research projects, are of course important but since a paper like this one cannot cover the entire field of energy-transition drivers and barriers, the ones in focus are the important ones for these particular communities as perceived by some of their key transition facilitators. 
Table 1. Main topics of conversation captured by ethnographic field study

\begin{tabular}{|c|c|c|}
\hline Communities & Sønderborg & Växjö \\
\hline General public & Strong opposition to further installation of wind turbines & $\begin{array}{l}\text { Växjö seen as a clean friendly place to live and raise children } \\
\text { Public very conscious about environmental matters } \\
\text { including supporting local industries } \\
\text { Desire to keep nature clean including keeping lakes clean } \\
\text { and picking of wild fruits } \\
\text { Not convinced with green branding of the city }\end{array}$ \\
\hline Political & $\begin{array}{l}\text { Keeping young people in the locality } \\
\text { Diversity of education, jobs and homes } \\
\text { Reusing former historic military buildings in town centre } \\
\text { Regional hospitals }\end{array}$ & $\begin{array}{l}\text { Promoting brand as Europe's Greenest City } \\
\text { Creating formal and informal partnerships to influence } \\
\text { national environmental policy and legislation } \\
\text { Promoting business sector } \\
\text { Providing exhibition halls for business and sports }\end{array}$ \\
\hline $\begin{array}{l}\text { Agricultural and } \\
\text { forestry sector }\end{array}$ & $\begin{array}{l}\text { Farmers keen to encourage the investment of wind } \\
\text { turbines on their land }\end{array}$ & $\begin{array}{l}\text { Largely silent stakeholder apart from presence of major } \\
\text { biomass power plants around the perimeter of the city that } \\
\text { supply district heating }\end{array}$ \\
\hline $\begin{array}{l}\text { Educational } \\
\text { sector }\end{array}$ & $\begin{array}{l}\text { Encouraging children interested in technology to be } \\
\text { part of a smart knowledge-based economy }\end{array}$ & $\begin{array}{l}\text { Linnaeus University } \\
\text { Focuses on engineering and technology in particular } \\
\text { renewable energy solutions } \\
\text { Act as a centre of excellence that attracts and helps retain } \\
\text { young people }\end{array}$ \\
\hline Business & $\begin{array}{l}\text { Danfoss } \\
\text { Exports to China for Smart Cities } \\
\text { Technological innovation for future home }\end{array}$ & $\begin{array}{l}\text { Lunchtime business meetings } \\
\text { Buying local and organic } \\
\text { Reduce waste (food) } \\
\text { Reduce energy (transport) }\end{array}$ \\
\hline Not for profit & $\begin{array}{l}\text { Project Zero } \\
\text { Focus on long-term vision for achieving zero } \\
\text { carbon dioxide emissions } \\
\text { Tackling opposition to wind turbines } \\
\text { Creating formal business partnerships with } \\
\text { Chinese cities }\end{array}$ & $\begin{array}{l}\text { Focus on long-term visions for reducing carbon dioxide } \\
\text { emissions; use of local resources for food, energy and } \\
\text { other needs of the community; increase environmental } \\
\text { education and awareness for widespread and sound ethical } \\
\text { fundamentals for behaviour change; strong ties with the } \\
\text { local private sector and international organisations for } \\
\text { increased sustainability; desire to be leading municipality } \\
\text { nationally and internationally in environmentally benign } \\
\text { behaviour; adapt infrastructure and activities to climate } \\
\text { change and its consequences }\end{array}$ \\
\hline $\begin{array}{l}\text { NGOs including } \\
\text { environmental }\end{array}$ & $\begin{array}{l}\text { Landsbylaugs concerned about protection of historic } \\
\text { buildings, and local customs plus how best to create } \\
\text { local job opportunities to retain young people }\end{array}$ & $\begin{array}{l}\text { Promoting urban gardening } \\
\text { Encouraging the purchase of organic produce. }\end{array}$ \\
\hline
\end{tabular}

The interview questions were all conducted in the language of the interviewees: in Danish in Sønderborg and Swedish in Växjö. The interviews were recorded with the interviewees' consent, transcribed and coded, but their results only presented anonymously, since the purpose with the research is to map what ideas and visions are around in the communities and not who has what opinion. The main topics of conversation captured by the field study are described in Table 1. These issues and more form the basis of the descriptive report presented as follows for both cities.

\section{City of Växjö}

\subsection{Environmental landscape}

Växjö is a medium-sized Swedish city with a population of 79000 inhabitants (Figure 1). It is the administrative, cultural and industrial centre of Kronoberg County in southern Sweden. The city was named 'Europe's Greenest City' by the BBC in 2007, which led to a massive interest in the city from policymakers, entrepreneurs and journalists from around the world eager to learn from its example. The genesis of Växjö's transition to being labelled 'Europe's Greenest City' lies in the 1970s, when the surrounding lakes had become seriously polluted and the inhabitants realised that the lakes had to be restored, otherwise irrevocable damage would be done (Emelianoff et al., 2014). This marks the start of awareness and the raising of people's consciousness, told by most as the origin of environmental consciousness and the trigger for change in resource management in the municipality. It initiated a care for nature and the community as a core characteristic of local identity, and started an ongoing process. Today it manifests itself in the desire drastically to reduce fossil fuel emissions and generate energy from local biomass. As such, Växjö’s success is closely connected with narrating the story of change and the creation of a local identity. This local identity portrays 'us' in the community as people who care for the environment, local 

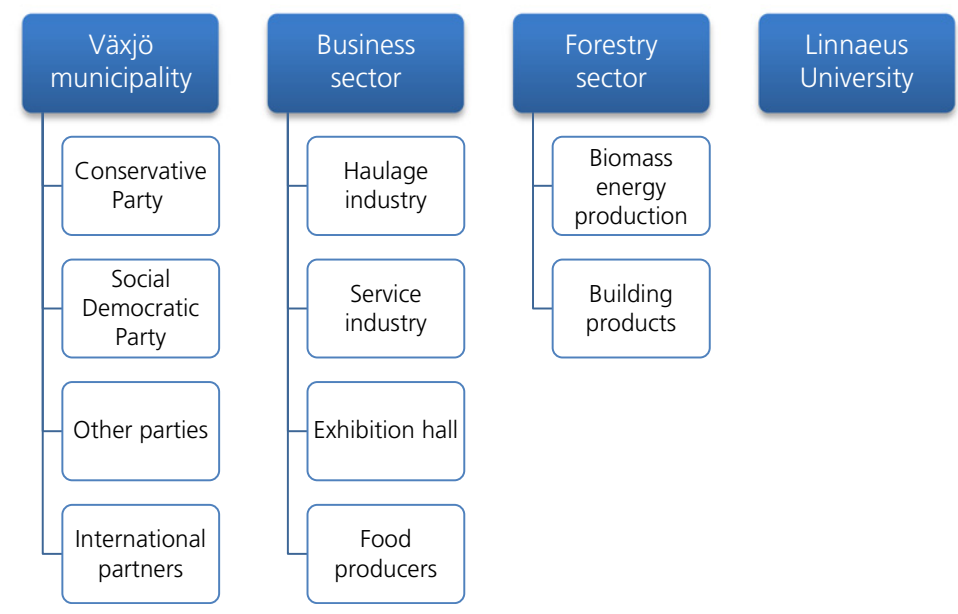

Figure 1. Map of different stakeholders present at Växjö forming part of the ethnographic field study

history and who want to use local resources wisely and to everyone's benefit, without polluting or destroying the environment.

The learning process from restoring the local lakes raised the consciousness of inhabitants about the precariousness of nature. This ethical base legitimised a pro-environmental behaviour and narrative that was adopted by the community. Knowing from experience that a badly degenerated environment affects human mental and physical health was a poignant lesson that people did not forget. However, the restoration of the lake system is not complete and there are still measures being taken to clean the remaining aquatic ecosystems. This experience adds weight to the importance of starting early and to being prepared for environmental changes to take decades or even longer. Hence, at the core of the story of transition is the interaction between people and nature that can improve everyone's health and well-being. Not surprisingly, the current environmental programme based on a vision for 2030 explicitly links liveability with nature (Växjö Municipality, 2014).

As a result, the grass-roots success in restoration of the local lakes noticeably gave inhabitants self-belief to make another transition. At the same time, the lake restoration raised other issues beyond the environment, namely $(a)$ the creation of jobs and other economic developments, (b) attraction of tourists, (c) halting the outward migration of the youth in the community. This positive narrative fed into a positive outlook towards adapting to climate change effects by making reductions in carbon dioxide emission through changes in energy generation and consumption. Repeatedly, it was a story about 'us', of Växjö's green life (Table 2).
Similar to the landscape of lakes and their restoration, Växjö is surrounded by forests, which dominate the topography, and have great historical importance. The forests contribute powerfully to the local identity about who 'we' are and what is special about 'us'. This local sense of identity cannot be underestimated. It is analogous to successful branding of urban communities for regeneration, where the branding process is authentic and owned by the community - such as the successful redevelopment of Katendrecht in the Nertherlands, a nineteenth century harbour zone, where local community groups insisted on retaining the historic identity (Eshuis and Edwards, 2015).

Furthermore, Växjö's economy relies greatly on forest products for building materials and as a source of energy from biomass (Dodoo et al., 2014; Mahapatra, 2015). The forests are seen as being natural, local and convenient and 'ours'. However, it is unclear if the resources of the forest are sufficient to meet future energy and construction demands, and whether the intact parts of the local forests can be left as such given that the municipality grows in population annually by approximately 1000 new inhabitants.

\subsection{Political landscape}

One of the most important features of Växjö’s success has been the role of consent across the political spectrum on environmental matters. Sometimes the narrative is given a green bias by attributing the achievements to a very active Green Party in the early 1990s that managed to 'green' the municipality's administration. In reality, the decision to reduce carbon dioxide emissions and adopt an ambitious programme for sustainable development was achieved by consensus across the political 
Table 2. Main features of the narratives depicting the green transition at Växjö and Sønderborg

\begin{tabular}{|c|c|c|}
\hline Stakeholders & Sønderborg & Växjö \\
\hline General public & $\begin{array}{l}\text { Largely disconnected and sceptical of renewable energy } \\
\text { from wind turbines }\end{array}$ & $\begin{array}{l}\text { Strong local identity based on shared history and } \\
\text { surrounding landscape } \\
\text { Strong environmental awareness } \\
\text { Confidence to tackle difficult environmental issues } \\
\text { having restored polluted lakes in } 1970 \text { s }\end{array}$ \\
\hline Political & $\begin{array}{l}\text { Acutely aware of the need to promote Sønderborg as an } \\
\text { exemplar city region in transition towards zero carbon } \\
\text { dioxide emissions in order to attract jobs to retain young } \\
\text { people in the community }\end{array}$ & $\begin{array}{l}\text { Political consensus between right wing and centralist } \\
\text { parties who are trusted by public to make the } \\
\text { right decisions for long-term benefits. } \\
\text { Formal and informal international partnerships seen } \\
\text { as a valuable strength when influencing national } \\
\text { legislation and regulations }\end{array}$ \\
\hline $\begin{array}{l}\text { Agricultural and } \\
\text { forestry sector }\end{array}$ & $\begin{array}{l}\text { Agricultural sector largely detached from PZ for cultural } \\
\text { reasons yet supporting investment in wind turbines }\end{array}$ & $\begin{array}{l}\text { Forestry sector largely silent stakeholder yet highly visible } \\
\text { with large biomass energy plants distributed around } \\
\text { the city }\end{array}$ \\
\hline Educational sector & $\begin{array}{l}\text { Local educational college largely focused on training skilled } \\
\text { workers for refurbishing energy-efficient buildings }\end{array}$ & $\begin{array}{l}\text { Local university acting as a magnet for young people to } \\
\text { study green technologies and subsequently stay locally }\end{array}$ \\
\hline Business sector & $\begin{array}{l}\text { Keen to form partnerships with public sector to } \\
\text { promote the take-up and showcasing of new } \\
\text { energy-efficient technologies. } \\
\text { Capitalising on interest from Chinese cities to transition } \\
\text { towards zero carbon dioxide emissions }\end{array}$ & $\begin{array}{l}\text { Using green strategy to remain competitive by reducing } \\
\text { waste and energy consumption, in particular from } \\
\text { transportation in haulage sector }\end{array}$ \\
\hline $\begin{array}{l}\text { Not-for-profit } \\
\text { sector }\end{array}$ & $\begin{array}{l}\text { PZ seen internally and externally as a great success bringing } \\
\text { private and public sector together by presenting } \\
\text { Sønderborg as a showcase for implementing of } \\
\text { low-carbon dioxide emission technologies at a city } \\
\text { region scale }\end{array}$ & \\
\hline
\end{tabular}

spectrum led by the right-wing or central administrations linked to a strong environmental identity. Fieldwork revealed that politicians were seen as having the courage to make decisions, based on long-term visions, even if it might not win them votes. This was brought up in many interviews and was said to make politics in Växjö different from many other municipalities, where a transition had not been successful or slower. Many pointed out that it did not matter whether the left, right or centre was in charge; putting sustainable development and emission reduction first had always been the leading thread on which political decisions had been based. The election system, with voting every 4 years, goes against this ability to see far ahead for decision making. It has been achieved at Växjö due to a strong environmental political vision in the community leadership.

Recently, the brand of being the 'Europe's Greenest City' encouraged local politicians to intensify the efforts by introducing an environmental programme approved by the Växjö Municipal City Council in 2014 (Växjö Municipality, 2014). The programme sets out an ambitious vision for 2030 with measurable environmental targets for three areas termed 'Living Life', 'Our Nature' and 'Fossil Fuel Free Växjö'. However, the field study revealed far less political consensus on fundamental social and economic problems facing the community, which results in less attention given to these issues and thus less discussion about and real measures taken in those fields of municipal management. It was pointed out by many interviewees that sustainable management is about all the three pillars - environmental, social and economic - and if one gets all the attention and resource, the other two lag behind, leading to token sustainable development and the problems just being pushed into the future, getting bigger and more severe.

Not surprisingly, the 'green' image has increasingly portrayed Växjö as an exemplar community for sustainable development underpinned by energy efficiency and renewable energy. This has resulted in countless visits from international delegations from elsewhere in Europe, China and globally as well as significant media attention. However, many interviewees did not always welcome the media attention and thought it placed undue strain on the community, diverting resources away from issues still to be resolved within the community. Although international recognition helped create strong external networks for Växjö, such as the Covenant of Majors, which would allow it to influence national and European energy policies, this was not always fully recognised or fully appreciated by the general public.

\subsection{Social landscape}

For many interviewees, trust was of central importance when considering public participation with municipal and/or state 
Transition of Växjö and Sønderborg

towards becoming fossil-fuel-free

communities

Dyer and Ögmundardóttir organisations and NGOs. The discussion raised questions about how to deal with pioneers and grass-roots activists who initiate the fight against environmental degradation, but often burn out or are forgotten, only to be rediscovered and recognised for their ground-breaking work when it is too late. This concurs with the past research findings of Seyfang (2010) and Seyfang et al. (2014) that emphasised the great importance attached to deep green values by grass-roots activists, rather than any tangible economic or material impacts.

Overall, many people within the community held opinions about a wide range of environmental matters and were aware of climate mitigation and adaptation measures that were underway. The story of Växjö's green life was widely shared and its core intact. Inhabitants saw themselves as a part of success and identity with it. Frequently, the core of the narrative for Växjö was raised in discussions, namely $(a)$ the co-operation between the municipal administration and the NGOs and other grass-roots organisations for the lake restoration, $(b)$ the management of the forest and the municipality's natural areas, $(c)$ the identification of social and economic problems that had to be tackled simultaneously with environmental ones and so on. The issues of $(a)$ how to engage and inform the public, and vice versa, $(b)$ how individuals and the public can initiate projects and (c) bridging the gap between politics and administration were voiced as being a common thread when telling the story of Växjö's transition.

\section{City of Sønderborg}

\subsection{Economic landscape}

Sønderborg is a coastal town in south-western Denmark, near the German border (Figure 2). It is located on the island of Als. The larger Municipality of Sønderborg comprises several additional smaller towns and a considerable area of agricultural land on both the island of Als and the mainland of Jylland, which stretches northwards out of mainland Europe. In 2012, the municipality was populated by a little over 76000 inhabitants. The region is, like most of Denmark, traditionally an agricultural area, but with several rather big companies, especially the manufacturing company Danfoss, as well as many other smaller industries and service businesses. Tourism is an important sector of the economy since Sønderborg is well known for its long stretches of beach and forests, as well as being a popular harbour for sailboats arriving from the Baltic Sea.

The story of Sønderborg's energy transition is newer than that of Växjö. It is based on a different set of drivers and takes place in a different historical and socio-economic context. The story is still in the making, not widely shared, more contested but highly interesting as the change has been successful so far and is happening at an impressive speed (Kristensen and

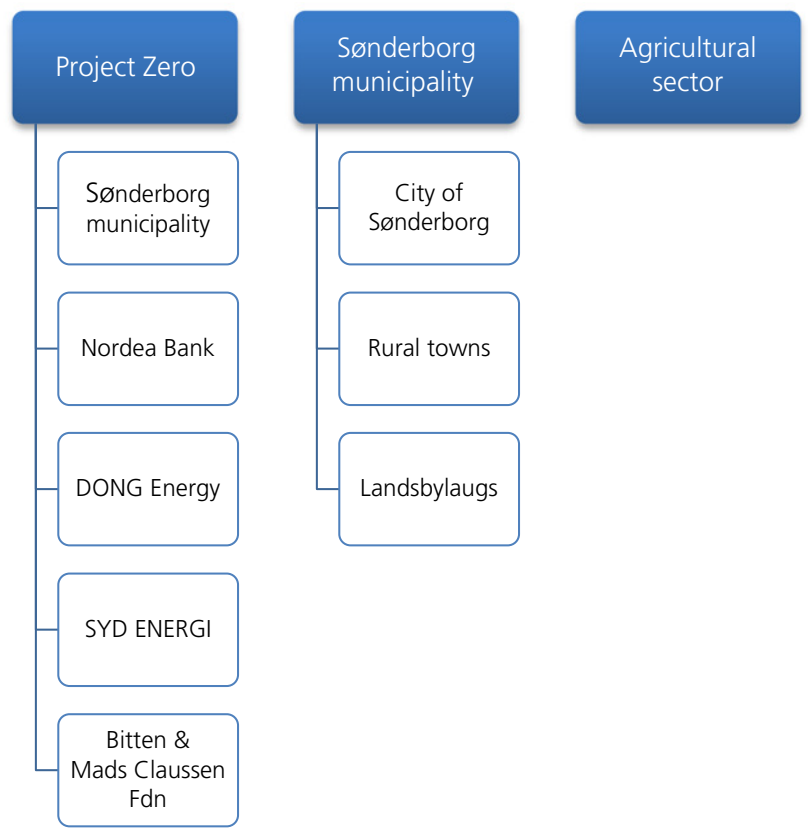

Figure 2. Map of different stakeholders present at Sønderborg forming part of the ethnographic field study

Dyhr-Mikkelsen, 2009). Here, it is interesting to follow how the identity of the community is taking on a green character, a process surprisingly smooth in many ways but also triggering controversies and difficulties.

\subsection{Business landscape}

The driving force for carbon dioxide emission reduction in the municipality is a local not-for-profit company called Project Zero (PZ). The company was established in 2007 by a consortium of local companies and the municipality authorities. The companies include Danfoss (Bitten \& Mads Clausen Foundation), SYD ENERGI, DONG Energy and the Nordea Bank. The entity PZ has one clear goal: the municipality is to emit zero carbon dioxide in 2029 as set out in PZ's master plan (Kristensen and Dyhr-Mikkelsen, 2009), with the added benefit of creating jobs.

From the outset, the secretariat and shareholders of PZ have used their local insider knowledge of the community to understand the socio-economic setting. The local characteristics of PZ were further strengthened by establishing close partnerships with local small- to medium-sized service and manufacturing companies, as well as the integration of PZ's vision into the municipal administrative fabric through frequent connections and close collaboration. The reference frame 'our identity' has a strong presence in the transition work, and trust is already underlying in communication and interaction, although it is 
Energy

Volume 171 Issue EN1
Transition of Växjö and Sønderborg

towards becoming fossil-fuel-free

communities

Dyer and Ögmundardóttir always a sensitive issue and sometimes challenged. The unbelievably high level of communication and constant networking, inside the community, has created stories and narratives about the energy transition. This approach was helped by the Danish culture of frequent formal and informal socialising, especially in the form of discussing any upcoming issue at length, more often than not with the aid of good food and beer, which is at the core of the successful networking observed during the research.

The employees were prepared at all times to reflect and change tactic as PZ goes through its many stages of development in a rapidly changing energy landscape. Many employees used expressions such as 'go with the flow', 'run ahead of the train and don't stop or it will hit you', and 'we really don't know what we're doing but we have to be brave enough to jump'. The use of metaphor in telling stories is a powerful tool. The image comes to mind of bold politicians, grass-roots leaders and ardent administrators, with long temporal visions, who 'jump' and thereby lead to fundamental changes; this was also one of the characteristics of success for Växjö. In Sønderborg, the PZ secretariat takes on this role to a greater extent, supported by a handful of municipal staff and leaders from the private sector, and as long as they are listened to by their private and public partners and given space and finance to work on their visions, the transition will go on for the next 15 years to reach the goal of zero emission in 2029.

One key interviewee stated that the project is at a threshold where the low-hanging fruits have been harvested and the more difficult phase of conquering areas of transition, where economic gains are much less obvious, lies ahead. This interviewee stated that to reach this next phase the key stakeholders have to realise that at the core of such a task is a change in outlook that involves a shared vision about why the transition has to be carried through. This runs considerably deeper than purely economic gains.

\subsection{Environmental landscape}

The emphasis on creating green jobs was felt to create an imbalance between the three columns of sustainable development, namely society, economy and environment. This was seen by the leaders of $\mathrm{PZ}$ as a weakness and potential threat but hard to tackle, and as such created a silence in discussion, which said more than words. Different from Växjö, there was a constant need to strike a balance between the different interests of the private partnership of $\mathrm{PZ}$, not least since much of the money to drive the $\mathrm{PZ}$ comes from private funding, and the deeper ethical concern of why the change has to take place.

Furthermore there was a weak connection between the PZ and environmental organisations at the grass-roots level in the community or region. This is in sharp contrast with the deep environmental undertones in Växjö, which are epitomised by the central role of its Naturskyddsförening in the onset of its green development and identity. To be sure, Sønderborg has its various citizen groups and NGOs in particular Landsbylaugs. In Sonderborg municipality, there are over 30 Landsbylaugs, many of which are very active in participating in the work towards zero-emission and low- and green-energy future. Landsbylaugs themselves are informal culture-based communities established for various types of co-operation and initiatives, such as common cultural and social events for the common good. However, overall these NGOs and Landsbylaugs are more heritage-focused on local architecture, food and customs. Hence, the situation in Sønderborg is a more complex one, leading to a higher level of disputes and uncertainty in the field. For example, wind energy has been in the forefront as a solution but is highly contested among the local stakeholders including Landsbylaugs, leading to political indecisiveness and unpredictability, and thus threatening any plans of emission reduction. The agricultural sector is not a key shareholder in PZ. Hence, the weak relationship has the potential to cause misunderstanding and lost opportunities for coordinating potential energy sources from agricultural waste or siting of wind turbine farms on private agricultural land. However, up to now, the PZ staff and their collaborators have been flexible and quick enough to seek alternative solutions.

\section{Discussion}

\subsection{Vision}

The ethnographic fieldwork offers a valuable comparison of the origins and characteristics of two quite different but highly effective local urban energy initiatives that, in one case, developed at a grass-roots level in the 1970s in Växjö based on ecological concerns that attracted the label of Europe's Greenest City compared with the neoliberal market-based PZ energy scheme at Sønderborg in the early 2010s that has generated local employment through building refurbishment schemes and attracting major international trade deals. Each initiative provides valuable social and political lessons beyond technological challenges that help overcome barriers when attempting to draw together different stakeholders to create a viable network for community-based energy initiatives.

In the case of Växjö, the common vision was one of protecting and valuing the environment through making good use of local resources, in particular from forestry, while avoiding waste and pollution. In addition, the presence of the local university acted as a magnet for young people to study and eventually settle in Växjö. In comparison, Sønderborg had a market-oriented focus on job creation and business opportunities. There was little mention of the environment in the Sønderborg vision. Besides, the agricultural sector was a missing ingredient in the creation of $\mathrm{PZ}$ given that farmers saw 
wind turbines as a valuable source of revenue. Even so, narratives for both cities were characterised by dynamic communication and networking backed by a political consensus that crossed party lines and was often led by right-wing conservative parties.

The observations appear to concur with the assessment of Seyfang et al. (2014) about how grass-roots innovations differ from market-based innovations in several key ways: the driving force is social and/or environmental need, rather than rent seeking; their context is civil society rather than the market economy; they display diverse organisational forms including co-operatives, voluntary organisations and community initiatives, rather than firms; their resource base is voluntary input, grant funding, mutual exchange and reciprocal relations rather than business loans and commercial income; they are grounded in local and collective values, based on notions of solidarity, rather than efficiency and profit seeking; and their niche protection consists of being a space for alternative - that is green, sustainability-oriented - values to be expressed, as opposed to shielding from market forces. In conclusion, they observed that although grass-roots innovations offered a promising yet neglected site of innovation for sustainability, they did not fit the governance prescriptions of strategic niche management. Instead, the sector requires imaginative policy support and recognition of its distinctiveness as an innovative sector beyond the typical commercial 'innovation' model.

\subsection{Narratives}

The fieldwork highlighted the importance of narrative to guide and motivate two quite separate and distinct communities towards an energy transition towards a fossil-fuel-free future. Interestingly, there was not one single narrative but instead several and sometimes contradictory stories, depending on who tells the story and for what purpose. This was seen as a positive sign of dynamic social interaction so long as there was common agreement about the main characteristics, moral fundamentals and future goals of transition. Even so, Växjö's and Sønderborg's transitions towards becoming fossil-fuel-free communities have faced several setbacks and disagreements. One of the main drivers of change has been the presence of dynamic and inclusive communication within the communities that allowed people to understand what was meant by change and to be motivated to participate. As such it is the content of the stories told and the morals taught that is the core message from the field study.

The narratives provided a shared experience and common platform for understanding and expressing the meaning and motivation for change. The empowering and dynamic elements of each narrative contribute crucially to the resilience of each transition, and can be seen as a vital tool for coping with an ever-changing world, and thus for adapting to the effects of climate change. Interestingly, the stories told by members of the communities often embraced the history of the communities' road towards increased sustainability, in terms of challenges to overcome and lessons learnt. Among the most empowering experiences in a community's transition was the experience of members taking on a challenge as a unit, as 'we', and turning its initial threat to their advantage.

\section{Conclusions}

In conclusion, the framework for transition used by both cities to move towards drastically reducing carbon dioxide emissions was found to have the following key characteristics.

(a) Strong local identity often rooted in history or a geographical dimension that is supported by a common narrative that vocalises main goals and the ethical basis for transition while celebrating success and accepting failure.

(b) Long-term political consensus and motivation based on at least one pillar of sustainable development (environmental, social, economic), while recognising that the other two pillars are highly relevant and ultimately essential.

(c) A platform for inclusive and continuous communication that allows reflection while enabling the narrative to evolve with time in response to changing circumstances.

(d) Dynamic individuals and organisations that have the passion and energy to form networks and capitalise on opportunities while overcoming setbacks.

(e) Strong external international partnerships that enable the local communities to influence national policy and regulation on sustainable energy.

The focus on economic issues and solutions can lock people's perception and articulation of the problems in a language of finance and accounting, excluding a wider discussion of value changes and the big picture of behavioural change. However, at the same time, the private sector is a powerful actor in any effort of change, not least when it comes to financing, and the story of Sønderborg's transition is testimony to the success of a public-private enterprise. After all, narrating the complex issues of energy transitions in culturally familiar terms, such as job-creation, monetary savings and technological innovation is probably much more potent in changing the public's behaviour than the spreading of abstract information about the conservation of species, rising temperatures and carbon dioxide concentration in the atmosphere.

\section{Acknowledgements}

The research is part of a 2-year post-doctoral project that Helga Ögmundardóttir has carried out since December 2012, as part of the 5-year research programme by the Nordic 
Centre of Excellence for Strategic Adaptation (NORD-STAR) (http://www.nord-star.info/), funded by the Norden Top-level Research Initiative sub-programme 'Effect Studies and Adaptation to Climate Change'. The authors thank leaders and fellow collaborators on the project, especially Brynhildur Davíðsdóttir, Peter Rathje and Jøran Solli. The authors also thank Günter Getzinger and other colleagues and staff of the Institute for Advanced Studies on Science, Technology and Society (IAS-STS) in Graz, Austria, for their input and aid, as well as John Sterman and colleagues at the Sloan School of Management, MIT, for an inspiring company and excellent table functions.

\section{REFERENCES}

Blanchet T (2015) Struggle over energy transition in Berlin: how do grassroots initiatives affect local energy policy-making? Energy Policy 78: 246-254.

Dodoo A, Gustavsson L and Sathre R (2014) Lifecycle carbon implications of conventional and low-energy multi-storey timber building systems. Journal of Energy and Buildings 8(2): 194-210.

Dovì V and Battaglini A (2015) Energy policy and climate change: a multidisciplinary approach to a global problem. Energies 8(12): 13473-13480.

EC (European Commission) (2011) Energy Roadmap 2050. European Commission, Brussels, Belgium, Comm (2011) 885/2.

Edenhofer O, Knopf B, Barker T et al. (2010a) The economics of low stabilization: model comparison of mitigation strategies and costs. Energy Journal 31(Special Issue): 11-48.

Edenhofer O, Knopf B, Leimbach M and Bauer N (2010b) ADAM's modeling comparison project - intentions and prospects. Energy Journal 31(Special Issue): 7-10.

Emelianoff C (2014) Local energy transition and multilevel climate governance: the contrasted experiences of two pioneer cities (Hanover, Germany, and Vaxjo, Sweden). Urban Studies 51(7): 1378-1393.

Eshuis J and Edwards A (2015) Branding the city: the democratic legitimacy of a new mode of governance. Urban Studies $\mathbf{5 0 ( 5 )}$ : 1066-1082.

Grubler A and Buettner T (2012) Urbanization past and future. In Energizing Sustainable Cities: Assessing Urban Energy (Grubler A and Fisk D (eds)). Taylor and Francis, London, UK, pp. 17-30.

Gustavsson L and Sather RA (2011) Energy and $\mathrm{CO}_{2}$ analysis of wood substitution in construction. Climatic Change 105(1): 129-153.

IEA (International Energy Agency) (2008) World Energy Outlook. IEA Books, Paris, France.

IEA (2013) Nordic Energy Technology Perspectives: Pathways to a Carbon Neutral Energy Future. OECD/IEA, Paris, France. See http://www.iea.org/etp/netp2013/ (accessed 28/11/2017).

Jörby S (2002) Local Agenda 21 in four Swedish Municipalities: a tool towards sustainability. Journal of Environmental Planning and Management 45(2): 219-244.

Komendantova N, Vocciante M and Battaglini A (2015) The BestGrid process: going beyond the existing practices of stakeholder involvement in electricity transmission projects? Energies 8(9): 9407-9433.

Kristensen T and Dyhr-Mikkelsen K (2009) Project Zero Masterplan 2009 for $\mathrm{CO}_{2}$ Neutral Sonderborg Region. SRC International Consultants, Sonderborg, Denmark.
Le Truong N, Dodoo A and Gustavsson L (2014) Effects of heat and electricity saving measures in district-heated multistory residential buildings. Journal of Applied Energy 118: 57-67.

Mahapatra K (2015) Energy use and $\mathrm{CO}_{2}$ emission of new residential buildings built under specific requirements - the case of Vaxjo municipality, Sweden. Journal of Applied Energy 152: 31-38.

Motosu M and Maruyama Y (2016) Local acceptance by people with unvoiced opinions living close to a wind farm: a case study from Japan. Energy Policy 91: 362-370.

Neuman W (2014) Social Research Methods: Qualitative and Quantitative Approaches, 7th edn. Pearson, Harlow, UK.

Rizzi F, Van Eck NJ and Frey M (2014) The production of scientific knowledge on renewable energies: worldwide trends, dynamics and challenges and implications for management. Renewable Energy 62: $657-671$.

Seyfang L (2010) Community action for sustainable housing: building a low-carbon future. Energy Policy 38(12): 7624-7633.

Seyfang G, Hielscher S, Hargreaves T, Martiskainen M and Smith A (2014) A grassroots sustainable energy niche? Reflections on community energy in the UK. Environmental Innovation and Societal Transitions 13: 21-44.

Smardon R (2008) A comparison of Local Agenda 21 implementation in North American, European and Indian cities. Management of Environmental Quality: An International Journal 19(1): 118-137.

van der Schoor T and Scholtens B (2015) Power to the people: local community initiatives and the transition to sustainable energy. Renewable and Sustainable Energy Reviews 43: 666-675.

van Sluisveld MAE, Harmsen JHM and Bauer N (2015) Comparing future patterns of energy system change in 2 degrees $C$ scenarios with historically observed rates of change. Global Environmental Change-Human and Policy Dimensions 35: 436-449.

Växjö Municipality (2014) Environmental Programme for the City of Växjö. Approved by the Municipal Council 2014-06-17. Växjö Municipality, Växjö, Sweden.

von Stechow C, Minx JC and Riahi K (2016) 2 degrees C and SDGs: united they stand, divided they fall? Environmental Research Letters 11(3): 34022.

Webb J, Hawkey D, McCrone D and Tingey M (2016) House, home and transforming energy in a cold climate. Families, Relationships and Societies 5(3): 411-429.

\section{How can you contribute?}

To discuss this paper, please email up to 500 words to the editor at journals@ice.org.uk. Your contribution will be forwarded to the author(s) for a reply and, if considered appropriate by the editorial board, it will be published as discussion in a future issue of the journal.

Proceedings journals rely entirely on contributions from the civil engineering profession (and allied disciplines). Information about how to submit your paper online is available at www.icevirtuallibrary.com/page/authors, where you will also find detailed author guidelines. 